\title{
ALGUNAS POSIBLES ENMIENDAS A LAS RIMAS DE LOPE A PARTIR DE LAS VERSIONES TEMPRANAS*
}

\author{
FERNANDO RodRÍGUEZ-GALLEGO \\ Universitat de les Illes Balears - IEHM \\ f.rodriguez-gallego@uib.cat
}

L

ope de Vega destaca en el panorama poético castellano de los siglos XVI y XVII por haber utilizado la imprenta como cauce fundamental de difusión de su poesía, frente a lo que sucedió con otros poetas canónicos de la época (Garcilaso, fray Luis de León, Aldana, Góngora, Quevedo...), cuyas poesías solo fueron impresas póstumamente, al margen de la edición ocasional de algunos poemas sueltos. Como recuerda Antonio Carreira, en el Siglo de Oro «hubo escritores que se negaron a imprimir sus obras, e incluso miraron con desdén a quienes hacían gemir las prensas» (2001: 21).

No fue este, sin embargo, el caso de Lope y su poesía, uno de cuyos grandes hitos lo encontramos en las Rimas, publicadas parcialmente en 1602 (los 200 sonetos) en el volumen La hermosura de Angélica con otras diversas rimas $\mathrm{y}$, en su forma definitiva, ya con el título de Rimas, en 1604, edición en la que se introducen modificaciones en los sonetos 2,3 y 44, se añaden sendos epígrafes en los sonetos 11, 26, 72 y 91, y se incluye, tras los 200 sonetos, una segunda parte con poemas métrica y temáticamente variados (Sánchez Jiménez y Rodríguez-Gallego, en prensa). La mayoría de los poemas contenidos en las Rimas solo se difundieron a través de la imprenta, y su transmisión textual, a partir de la edición de 1604 (que incluye algunas correcciones del autor), es estrictamente lineal (Pedraza Jiménez, 1993-1994: I, 104). Sin embargo, otros poemas, normalmente sonetos escritos ya hacía tiempo y que fueron (re)utilizados en las Rimas, se han conservado también en manuscritos (hemos localizado 62,

\footnotetext{
* Este trabajo se ha beneficiado de mi participación en los proyectos de investigación con referencias PGC2018-094395-B-I00 y PGC2018-096004-A-I00 (MCIU/AEI/FEDER, EU).
}

Edad de Oro, XXXIX (2020), pp. 221-235, ISSN: 0212-0429 - ISSNe: 2605-3314 DOI: https://doi.org/10.15366/edadoro2020.39.012 
de diferente valor, que contienen al menos un texto de las Rimas $)^{1}$ o fueron incluidos en comedias, por lo que pueden presentar variantes de importancia, en muchos casos autoriales.

La difusión de algunos sonetos de las Rimas antes de la inclusión de los textos en la edición de 1602 fue muy notable. Así, los manuscritos que han conservado sonetos como el 20 («Si culpa el concebir, nacer tormento»), el 64 («Yo vi, sobre dos piedras plateadas») o el 191 («Es la mujer del hombre lo más bueno»), los tres más difundidos del corpus, se acercan a la veintena, lo que hace que las variantes, de mayor o menor relevancia, aumenten exponencialmente.

En todo caso, estas versiones manuscritas o contenidas en comedias han tendido a considerarse muy valiosas con respecto a la génesis de los textos (pueden verse, por ejemplo, Montesinos, 1967: 109-120; Lázaro Carreter, 1992: 162-166; McNair, 2005), pero no tanto para la fijación definitiva de estos. Es decir, vienen a interesar más a la genética textual (con el inconveniente de no ser siempre fácil discernir entre variantes de copista y de autor) que a la crítica textual propiamente dicha, que ha considerado la versión de las Rimas la definitiva y solo ha atendido a las posibles modificaciones que haya podido introducir Lope en las diferentes ediciones de estas. Así, las dos ediciones críticas de las Rimas que se han publicado hasta la fecha, las de Felipe Pedraza (1993-1994) y Antonio Carreño (1998), que discrepan entre sí en cuanto a la edición de las Rimas que han utilizado como texto base - la sevillana de 1604 en el caso de Pedraza (1993-1994: I, 118-119), la madrileña de 1609 en el de Carreño (1998: CII)—, sí coinciden en no haber modificado el texto que seguían para acoger variantes de versiones anteriores conservadas en manuscritos o comedias, que relegan siempre al aparato.

Sin embargo, he detectado algunos lugares, más o menos dudosos y de distinta relevancia, en los que la consulta de estas versiones más tempranas invita a pensar que en la primera edición de las Rimas pudo haberse deslizado un error que pasó inadvertido tanto en la de 1604, corregida en algunos textos por Lope, como en las sucesivas. El primero lo encontramos en el soneto 18 ( «Píramo triste, que de Tisbe mira»), vv. 9-11:

Lamentablemente, no hemos tenido acceso a la base de datos Bibliografía de la Poesía Áurea (BIPA), preparada por Ralph DiFranco y José J. Labrador Herraiz, pues todavía no está en acceso abierto. Seguramente, cuando esté disponible para público e investigadores, pueda aumentarse el número de manuscritos que conservan versiones de las Rimas, dado el ingente trabajo realizado por ambos profesores en las últimas décadas. Véase DiFranco y Labrador Herraiz (2001). 
$A^{2}$

Tisbe vuelve y le mira apenas, cuando arroja el blanco pecho al hierro fuerte, más que de sangre de piedad desnudo.
Biblioteca Nacional de España, ms. 3.890

Tisbe le busca y mira apenas, cuando arroja el blando pecho al hierro fuerte, más que de sangre de piedad desnudo.

La variante «blanco-blando» ya llamó la atención de Felipe Pedraza, quien, aunque editó «blanco», de acuerdo con el texto de las Rimas, aventuró en nota que el sorprendente paso de «blando» a «blanco» en este verso tal vez se debiese a una errata (1993-1994: I, 224). En efecto, cuesta trabajo pensar que haya sido Lope quien cambiase el adjetivo «blando», que establece una intensa antítesis con «fuerte», por «blanco», adjetivo que acompañaba a «pecho» con mucha frecuencia en textos áureos, también de Lope, lo que invita a pensar en una lectio facilior introducida por el cajista de $A$.

Una variante que encontramos en La corona merecida parece sustentar esta hipótesis de que Lope escribió «blando», lectura modificada en «blanco» por algún cajista. En los vv. 665-666 de la comedia, Lope escribió en el autógrafo, de su puño y letra: «Es de un cisne su garganta / en blandura y en color» (Vega Carpio, 2015: 665), lectura que se modificó, posiblemente de manera ajena a Lope, al ser editada la obra en la Parte XIV en «Es de un cisne su garganta / en blancura y en color». Esta variante podría ser vista como argumento a favor de enmendar también este lugar de las Rimas.

Sin embargo, cabe ser cautos. En el TESO, mientras que solo se encuentra una ocurrencia de «blando pecho» en textos de Lope, son nada menos que once aquellas en las que es «blanco» el adjetivo que lo acompaña, entre las que podemos destacar dos, por su contexto en parte similar al de este soneto de las Rimas. En Los Ramírez de Arellano dice don Enrique, tratando de la muerte de su madre:

Dejole, según me han dicho,

todo el puñal alevoso

metido en el blanco pecho

(Vega Carpio, 1954: 157, vv. 855-857).

En El caballero del Sacramento, narrando cómo una armada se lleva a la bella doña Gracia, traza el capitán el siguiente símil:

2 Utilizo la sigla $A$ para referirme a la primera edición de los doscientos sonetos, incluida en el volumen La hermosura de Angélica con otras diversas rimas, Madrid, en la imprenta de Pedro Madrigal, 1602. Si no se indica lo contrario, las lecturas de $A$ fueron mantenidas por las ediciones posteriores de las Rimas. 
y como el gavilán cuando se ceba el blanco pecho de la presa amada entre el pico y las uñas, de quien fueras águila caudalosa si le vieras

(Vega Carpio, 2016a: 618, vv. 1.382-1.385).

Parece, pues, que la fórmula «blanco pecho» era del agrado del poeta y, tal vez de haber escrito «blando» en una primera versión, quiso modificarlo por «blanco» al incluir el soneto en las Rimas, si es que la variante «blando» no es de copista, atraída precisamente por la antítesis con el «hierro fuerte». A la vista de la variante de La corona merecida, no cabe descartar, sin embargo, que no haya sido Lope el responsable de introducir la variante «blanco».

Un nuevo pasaje dudoso aparece en el soneto 52, vv. 1-8:

$A$

Entre aquestas colunas abrasadas, frías cenizas de la ardiente llama de la ciudad famosa que se llama ejemplo de soberbias acabadas; entre estas otro tiempo levantadas, y ya de fieras deleitosa cama, entre aquestas rüinas, que la fama por memoria dejó medio abrasadas;
Biblioteca Nacional de España, ms. 2.856 / El ganso de oro

Entre aquestas colunas derribadas, frías cenizas de la ardiente llama de la ciudad famosa que se llama ejemplo de soberbias acabadas; entre estas otro tiempo levantadas, y ya de fieras deleitosa cama, entre aquestas rüinas, que la fama por memoria dejó medio abrasadas;

Como puede observarse, además de la fea rima asonante entre todos los versos de los cuartetos, en $A$ se repite «abrasadas» en posición de rima en vv. 1 y 8 , lo que no parece muy feliz, aunque tampoco es algo completamente extraño en Lope ${ }^{3}$. Sin embargo, en las versiones tempranas del soneto que nos han llegado en la comedia El ganso de oro ${ }^{4}$ y en el ms. 2.856 de la Biblioteca Nacional de España, no se produce esta repetición, ya que leen, en el primer verso, «derribadas». Resulta difícil asumir que, partiendo de la lectura «derribadas», Lope decidiese modificar el adjetivo para cambiarlo por «abrasadas», con lo que se reitera el que ya utiliza en v. 8. ¿Será, pues, error de $A$ que se transmitió a todas las ediciones posteriores? En la versión inicial, «derribadas» establecía un fuerte contraste con «levantadas» (v. 5), que se pierde en la versión de las Rimas, en la que, al contrario, se gana uno

\footnotetext{
3 No es el único lugar de las Rimas en que sucede. Así, en el soneto 134 se repite el adjetivo «provechosa» en posición de rima en los vv. 1 y 5 . En vv. 2-3 del soneto que nos ocupa también repitió Lope la misma palabra en posición de rima, «llama», aunque en realidad es un caso de dos palabras distintas, pero homófonas: un sustantivo en v. 2, una forma verbal en v. 3.

4 El ganso de oro se ha conservado en el ms. II/463(5) de la Real Biblioteca, ff. 89-110. El soneto se encuentra en el f. 98 r.
} 
nuevo entre «abrasadas»y «frías» (vv. 1-2). Además, las «cenizas» y la «ardiente llama» del v. 2, que remiten a un campo semántico más cercano a lo «abrasado» que a lo «derribado», tal vez atrajesen el error de copia. La hipótesis del error parece más plausible que el atribuir la variante al propio Lope, aunque quizá este en un primer momento escribiese «derribadas», que cambió después en «abrasadas» buscando ese contraste con «frías», sin percatarse de que usaba la palabra más adelante, también en posición de rima.

En este caso los lugares paralelos ayudan menos, pues tanto «derribadas» como «abrasadas» son términos genuinos de Lope y aparecen en contextos similares. En todo caso, sí cabe constatar el uso de «derribadas» por parte del Fénix, ya en las propias Rimas, en la epístola «Al contador Gaspar de Barrionuevo», donde la aplica en v. 249 a unas paredes (Vega Carpio, 1993-1994: II, 297). De manera más interesante, en la Jerusalén conquistada el adjetivo se aplica al sustantivo «colunas» y en contexto amoroso, como en el soneto de las Rimas:

$$
\begin{aligned}
& \text { Cuatro colunas derribadas veo } \\
& \text { del edificio de mi amor y casa } \\
& \text { y la basa mayor de mi trofeo, } \\
& \text { que le fundé sobre tan fuerte basa }
\end{aligned}
$$

(Vega Carpio, 1951: 183).

En el soneto 56 («Que eternamente las cuarenta y nueve»), se lee así en los tercetos (vv. 9-14):

\section{A}

que pague Prometeo el loco aviso de ser ladrón de la divina llama en el Caucaso que sus brazos liga, terribles penas son, mas de improviso ver otro amante en brazos de su dama, si son mayores, quien lo vio lo diga.
Los palacios de Galiana / Theatro de los dioses de la gentilidad que pague Prometeo el loco aviso de ser ladrón de la divina llama en el Caucaso que sus miembros liga, terribles penas son, mas de improviso ver su amante en los brazos de otra dama, si son mayores, quien lo vio lo diga.

En una versión temprana del soneto, contenida en la comedia Los palacios de Galiana ${ }^{6}$, en el v. 11 se lee «miembros», lectura que pasó a «brazos» en las Rimas. En principio, podría pensarse que se trata de una variante introducida por Lope, por las razones que fuesen. Sin embargo, hemos de notar que la palabra «brazos»

\footnotetext{
5 En la obra el soneto lo recita Armelina, que lo ajusta a su situación dentro de la trama.

6 La comedia fue publicada en la Parte veinte y tres de las comedias de Lope Félix de Vega Carpio, Madrid, por María de Quiñones, a costa de Pedro Coello, 1638, ff. 230v-257v (el soneto se encuentra en el f. $237 \mathrm{v}$ ).
} 
se repite en el v. 13, de tal manera que quizá la lectura de $A$ se deba más bien a un error atraído por la presencia de «brazos» dos versos después. En este caso hemos de añadir, además, un pequeño elemento sorprendente, debido a la presencia del soneto en el Theatro de los dioses de la gentilidad de Baltasar de Vitoria, publicado en 1620. El soneto se encuentra en la p. 560 y su texto, aunque coincide con la versión de las Rimas (como sucede en otros poemas de la colección incluidos en el Theatro), presenta también en este verso la variante «miembros». Da la impresión, pues, de que en el Theatro se quiso corregir la versión de las Rimas, tal vez por conocerse la de Los palacios de Galiana, si es que no fue indicación del propio Lope, quien firmó una aprobación del Theatro.

Otro posible error de los impresos lo encontramos en el conocido soneto 126 («Desmayarse, atreverse, estar furioso»), estudiado entre otros por Profeti (1986: 537-538) y Pedraza Jiménez (1993-1994: I, 35-37), y cuyos tercetos leen así, vv. 9-14:

$A$

huir el rostro al claro desengaño; beber veneno por licor süave; olvidar el provecho, amar el daño; creer que un cielo en un infierno cabe; dar la vida y el alma a un desengaño: esto es amor; quien lo probó lo sabe.

\section{Poética silva}

huir el rostro al claro desengaño; al veneno llamar licor süave; olvidar el provecho, amar el daño; creer que el cielo en el infierno cabe; dar la vida y el alma a un dulce engaño: esto es amor; quien lo probó lo sabe.

En un manuscrito conocido como Poética silva y conservado en el fondo Rodríguez Moñino de la biblioteca de la Real Academia Española (RM-6.898) se copió una versión temprana de algunos sonetos de las Rimas, entre ellos, el 126 (Osuna, 2000: I, 259). Las diferentes variantes entre ambas versiones nos permiten observar el proceso de reescritura del soneto, pero más llamativa resulta la del v. 13. La lectura de los impresos, «desengaño», parece errónea: por un lado, repite la palabra en posición de rima del v. 9; por otro, parece romper con el discurso presente en los tercetos, en los que se acumulan situaciones en las que el hablante, enamorado, abraza aquello que le perjudica (bebe veneno, ama el daño) y rechaza lo que podría beneficiarle (huye el desengaño, olvida el provecho). En este contexto, no tiene sentido que el yo lírico entregue la vida y el alma a un «desengaño», pues esto sería lo esperable desde una perspectiva racional, para luchar contra el «engaño» propio del amor. En la lógica del enamoramiento, ajena a la del mundo cotidiano, el desengaño, según dice el v. 9, debe evitarse, no buscarse, de tal manera que, en los impresos, los vv. 9 y 13 se contradicen. En el contexto del poema tiene más sentido dar la vida y el alma «a un dulce engaño», según se expresa en el manuscrito. 
La variante de la Poética silva llamó ya la atención de Pedraza, quien apunta que el manuscrito «trata de enmendar la rima con la misma palabra [de los impresos]» (1993-1994: I, 461, n. 13), palabras también citadas por Osuna en su aparato crítico de la versión manuscrita (2000: II, 98). Sin embargo, la Poética silva tiende a presentar versiones tempranas de los sonetos de las Rimas que contiene (así sucede con sus versiones de los poemas 61, 64 y 162), por lo que parece plausible que «dulce engaño» sea una lectura genuina, y no un intento de enmendar un texto anterior. De ser esto cierto, podría pensarse que la lectura «desengaño» constituye un error por repetición introducido en $A$, favorecido por la «d» inicial tanto de «dulce» como de «desengaño», que se transmitió al resto de ediciones.

Además, la lectura del manuscrito parecen sustentarla otros lugares de las Rimas, como los vv. 12-14 del soneto 101, donde se reitera el sintagma «dulce engaño», que se opone a «desengaño»:

Pluguiera a Dios duraras, dulce engaño: que, si ha de dar un desengaño muerte, mejor es un engaño que da vida

(Vega Carpio, 1993-1994: I, 407).

De igual manera, en versos que intercambian doña Juana y su criada Lucía en La fortuna merecida se contraponen el «dulce engaño» y el «desengaño»:

JuANA En vano sigo un loco pensamiento.

Lucía En vano sigo, amor, un dulce engaño. [...]

JUANA ¡Oh, si olvidase yo con desengaño!

Lucía ¡Oh, si pudiese yo mudar de intento!

(Vega Carpio, 2012a: 705, vv. 1.383-1.390).

En La locura por la honra se queja el conde de los memoriales que recibe:

Otro [memorial] de los amantes que hacen cargo

a las mujeres a quien han servido

del dulce engaño y desengaño amargo

(Vega Carpio, 2012b: 291, vv. 2.324-2.326).

También en estos versos de El peregrino en su patria aparece «dulce engaño» en posición de rima, en contexto en el que se contrapone al «desengaño»:

Mas como en desventuras manifiestas

suele ser tan costoso el desengaño

y sus veloces alas son tan prestas, 
vencido de la fuerza de mi daño, caí desde mí mismo medio muerto y conmigo también mi dulce engaño

(Vega Carpio, 2016b: 391).

En estos versos de La Dorotea encontramos asimismo el «dulce engaño», al que de nuevo pone fin el «desengaño»:
Mi propia voz me engaña, $\mathrm{y}$, como voy tras ella, cuanto la sigo y llamo, tanto de mí se aleja. En este dulce engaño, pensando que me espera, salen del alma sombras a fabricar ideas.
Delante se me ponen, y yo, con ansia estrema, lo que imagino abrazo, por ver si efeto engendra. Pero en desdicha tanta, y en tanta diferencia, los brazos que engañaba, desengañados quedan

(Vega Carpio, 2011: 167).

En un hermoso soneto que recita la condesa en Las flores de don Juan y rico y pobre trocados, los engaños del amor llegan a ser «dulcísimos»:

Amor, yo te agradezco las porfías con que tantos dulcísimos engaños rindieron hoy las altivezas mías

(Vega Carpio, 2013: 321, vv. 2.757-2.759).

En otro soneto, incluido en la comedia El conde Fernán González, el «dulce engaño» se combina con otro elemento presente en el soneto 126 , beber veneno:

Los venenos bebidos hacen daño, pero ¿cuándo, escuchados, los venenos se han dado a nadie con tal dulce engaño?

(Vega Carpio, en prensa: vv. 1.884-1.886). 
Incluso en un contexto tan diferente como el de una sátira, de autoría incierta aunque posiblemente escrita por Lope, encontramos la oposición entre «dulce engaño» y «desengaño»:

Detúvome el amor, el dulce engaño de aquel tu gran motor, tu entelequía, pero quiérote dar un desengaño

(vv. 201-203, en Tubau, 2008: 169)

Todos los textos citados, que aún podrían ser más, parecen confirmar que «dulce engaño» es, al menos, lectura genuina de Lope, o propia de su usus scribendi, por lo que no debe de ser un intento de corregir la repetición de los impresos, sino, más bien, la primera redacción del lugar, acaso corrompida, en un error por repetición, en $A$.

Otro posible error de los impresos lo encontramos en el soneto 170, vv. 1-4:

\section{A / El grao de Valencia}

No tiene tanta miel Ática hermosa, algas la orilla de la mar, ni encierra tantas encinas la montaña y sierra, flores la primavera deleitosa,
Real Academia Española, RM-6213 / Biblioteca Nacional de España, ms. 3.907

No tiene tanta miel Ática hermosa, algas la orilla de la mar, ni encierra tantas encinas la Morena Sierra, flores la primavera deleitosa,

En principio, podría pensarse que la variante del v. 3 presente en dos manuscritos, «la Morena Sierra», es equipolente, pero un lugar del soneto 153, vv. 1-4, siembra la duda:

$$
\begin{aligned}
& \text { Si la más dura encina que ha nacido } \\
& \text { del corazón de la Morena Sierra, } \\
& \text { o el Alpe en su nevada cumbre encierra, } \\
& \text { fiero desdén, te hubiera producido }
\end{aligned}
$$$$
\text { (Vega Carpio, 1993-1994: I, 519). }
$$

En este caso todos los testimonios coinciden en la lectura «Morena Sierra», que se pone en relación con la «encina» del v. 1. Por ello, tal vez podría pensarse que también en el soneto 170 la lectura correcta es «Morena Sierra», de nuevo relacionada con «encinas», y que «montaña y sierra» es lectio facilior que se introdujo en $A$ por no entenderse la lectura «morena» y pasó a los demás testimonios. Además, la mención del Ática en el primer verso parecería hacer preferible también aquí la alusión a un lugar concreto, no indeterminado.

Sin embargo, en este caso un argumento textual invita a la prudencia, pues en la versión del soneto incluida en la comedia El grao de Valencia, conservada 
en un ms. II/460 (1) de la Real Biblioteca, se lee también «montaña y sierra», lo que inclina a pensar que se trata de una lectura genuina de Lope. También en $L a$ campana de Aragón encontramos el sintagma:

Fïeme de los crïados, que agora parten con ella, y publico que es don Juan por esta montaña y sierra

(Vega Carpio, 2019: 364, vv. 810-813).

En la edición que acaba de terminar de El grao de Valencia, Daniel Fernández Rodríguez (en prensa) opta por enmendar el texto del soneto de acuerdo con la lectura de los manuscritos, y explica:

La presencia de la variante Morena Sierra en dos manuscritos, los profundos paralelismos estilísticos de este pasaje con el soneto 153 de las Rimas, las incongruencias de la lección montaña y sierra en su contexto inmediato y el carácter a todas luces difficilior de Morena Sierra me llevan a suponer que la lección del manuscrito es el resultado de un error de copia o de una corrección desafortunada, quizá producido por cierta extrañeza ante la lectura (con minúsculas) morena sierra.

La enmienda es plenamente plausible, pero se hace más difícil de adoptar en las Rimas. Suponiendo que Lope haya escrito inicialmente «Morena Sierra», resulta factible que el verso se corrompa en «montaña y sierra» en El grao de Valencia, obra que se ha conservado en un único manuscrito, pero ¿cómo es que reaparece «montaña y sierra» en las Rimas? Al prepararlas, Lope reescribe parcialmente el soneto e incluye el nombre de Lucinda en el v. 14, de acuerdo con el discurso general de las Rimas. Así, para sostener que «montaña y sierra» es lectura errónea, habría que suponer que Lope reescribe el texto a partir de una copia que ya tenía el error, y no a partir de un borrador que pudiese haber conservado él, y que Lope no se da cuenta del error «montaña y sierra» y lo mantiene. Por ello, quizá sea más prudente mantener la lectura «montaña y sierra» en el soneto de las Rimas, a pesar de que «Morena Sierra» parece a todas luces mejor y difficilior.

Una última variante problemática de las ediciones de las Rimas, y más a la vista de las versiones manuscritas, la encontramos en el muy difundido soneto 191, vv. 1-4:

Es la mujer del hombre lo más bueno y locura decir que lo más malo; su vida suele ser, y su regalo; su muerte suele ser, y su veneno

(Vega Carpio, 1993-1994: I, 601). 
En el soneto se alternan dos perspectivas sobre la mujer: una positiva y una negativa (Alatorre, 2000: 318). Por ello, el v. 2, que, por el contrario, insiste en lo que se ha indicado en el v. 1 (o, mejor dicho, niega la posibilidad contraria), rompe con lo esperable dentro del discurso del soneto, como ya puso de relieve don Cayetano Rosell en su antología de 1856, en la que escribió: «Esta palabra [locura] destruye la idea fundamental del soneto. Acaso Lope escribiría lo fuera» (1856: 353).

Aunque la enmienda que propone Rosell no es muy afortunada, las versiones tempranas sí parecen confirmar su intuición en torno al carácter anómalo del v. 2 del soneto. Así, en su mayoría proponen una lectura directamente inversa del v. 1: «Es la mujer del hombre lo más malo», que sí se ajusta a la perfección al discurrir del soneto. Sin embargo, la diferencia entre «Es la mujer del hombre» y «y locura decir que» es demasiado grande como para pensar en un error mecánico o de copia en el texto de los impresos. Tampoco se aprecia una manera sencilla de salvar la lección de estos o modificarla mínimamente, pues parece muy forzado entender el verso como interrogativo («¿y locura decir que lo más malo?»), o bien ensayar una división de palabras diferente («y lo cura decir que lo más malo»; pero ¿qué es lo que cura?). Da la impresión, más bien, de que Lope quiso modificar la lectura de la redacción primitiva, aunque en la revisada se introdujo un error, difícil de precisar.

Frente a otros manuscritos que recogen versiones tempranas, en el 4.140 de la Biblioteca Nacional de España se copia una versión del soneto que coincide en lo fundamental con la de las Rimas, con respecto a la cual solo presenta una variante de importancia, precisamente en este v. 2: «y se puede decir que lo más malo». En el Catálogo de manuscritos de la Biblioteca Nacional sitúan este en el siglo XVII, y dicen sobre él: «se trata de un excelente cancionero del abad Maluenda, aderezado con otras composiciones de otros autores, y copiado por mano autorizada, que corregía frecuentemente los versos» (1998-2008: III, 1.985-1.986). Además del 191, se copian en este manuscrito los sonetos 20 y 132 de las Rimas, este último con atribución a Céspedes. Las variantes introducidas en ambos no son de gran importancia, aunque no parece que se estuviese copiando el texto de las Rimas, como indica, además, la atribución a Céspedes del 132. Existen, por ello, dos posibilidades fundamentales ante la variante del soneto 191: o bien el manuscrito contiene la versión definitiva, alterada por error en $A$; o bien la versión del manuscrito es un intento de enmendar la de los impresos, aunque en el manuscrito no hay correcciones de ningún tipo. Cabe mencionar también que la variante del manuscrito amortigua el carácter dialógico que tenía el soneto en su redacción primitiva, en la línea de otras variantes que se introducen con respecto a esta ${ }^{7}$. En todo caso, la distancia entre

7 Por ejemplo, en vv. 5-6 varias versiones tempranas leen: «Es vaso de bondad y virtud lleno. / A un áspid libio su ponzoña igualo», lectura que mantiene el carácter dialogístico que había apuntado Alatorre con respecto al soneto, como si el v. 5 lo dijese un defensor de la mujer, y el 6, 
la variante del texto del manuscrito y la lectura de las Rimas quizá aconseje, por prudencia, mantener esta y dejar constancia del problema ${ }^{8}$.

Como ha podido comprobarse, los pasajes examinados no son de la misma entidad, de igual manera que la posibilidad de que exista un error en el texto de las Rimas es más o menos dudosa según el pasaje de que se trate. En todo caso, enmendar un texto que ha sido preparado o supervisado por el mismo Lope produce cierto vértigo y es tarea que ha de ser justificada con seriedad. Pero no es menos cierto que, aunque Lope haya sido el responsable de la publicación de los sonetos, tal hecho no nos garantiza que se trate de un texto sin errores, dada además la facilidad con la que se podían introducir en las prensas manuales. Lope, además, aunque debió de cuidar con cierto esmero el texto de los sonetos en la edición de 1602, parece haberse despreocupado de él en ediciones posteriores: en la de 1604 introdujo las variantes ya mencionadas al principio del artículo, pocas y muy localizadas, pero no parece haber revisado el texto de los demás sonetos, como tampoco debió de hacerlo en ediciones posteriores; es decir, de haberse introducido algún error en la edición de 1602, este se habría mantenido en las ediciones siguientes, salvo en casos de erratas o errores evidentes. Por ello, el atento examen de las versiones tempranas de algunos sonetos de las Rimas, además de permitirnos analizar el proceso de reescritura que experimentaron varios de ellos con vistas a su inclusión en las Rimas, podrá poner de manifiesto, en las versiones impresas, la existencia de algunos errores, o al menos de lugares problemáticos que merecen un comentario o alguna reflexión en torno a ellos.

\section{BiBLIOGRAFÍA}

Alatorre, Antonio (2000). «De Góngora, Lope y Quevedo». Nueva Revista de Filología Hispánica, 48, pp. 299-332.

CARREIRA, Antonio (2001). «El manuscrito como transmisor de las humanidades en los Siglos de Oro». Boletín del Instituto de Investigaciones Bibliográficas, 6, 1-2, pp. 21-46.

Carreño, Antonio (1998). Ver Vega Carpio (1998).

Catálogo de manuscritos de la Biblioteca Nacional con poesía en castellano de los siglos XVI y XVII (1998-2008). Pablo Jauralde Pou (dir.). Madrid: Arco Libros.

un detractor. En las Rimas, sin embargo, los versos pasan a «Cielo a los ojos cándido y sereno / que muchas veces al infierno igualo», lectura que, aunque mantiene la alternancia entre aspectos positivos y negativos de la mujer, parte de una voz única, como sucede también en los vv. 1-2 de acuerdo con la variante manuscrita mencionada.

8 El carácter anómalo del v. 2 en la versión de las Rimas se observa también, indirectamente, en el texto del soneto copiado en el manuscrito Mib AD. XI.57 de la Biblioteca Braidense de Milán, pues coincide en su integridad con el de las Rimas salvo en el v. 2, en el que se recupera la versión temprana «Es la mujer del hombre lo más malo». 
DiFranco, Ralph A. y José J. Labrador Herraiz (2001). «Bibliografía de la Poesía Áurea. Banco de datos preparado por Ralph A. DiFranco y José J. Labrador Herraiz. Muestra de las virtudes que dicho instrumento aporta a quienes se entretienen con el honrado oficio de estudiar la poesía de los siglos XVI y XVII». eHumanista: Journal of Iberian Studies, 1, pp. 54-84.

Fernández Rodríguez, Daniel (ed.) (en prensa). «Lope de Vega, El grao de Valencia». En: Gondomar Digital. La colección teatral del conde de Gondomar < gondomar.unibo.it>.

LÁzAro CARreter, Fernando (1992). «Lope, pastor robado». En Estilo barroco y personalidad creadora. Madrid: Cátedra, pp. 149-167.

McNaIr, Alexander J. (2005). «Definitions and Enigmas: the Textual Transmission of Lope de Vega's Sonnet 191 (Rimas)». Hispanófila, 145, pp. 1-18.

Montesinos, José F. (1967). Estudios sobre Lope de Vega. Salamanca: Anaya.

OsunA, Inmaculada (ed.) (2000). Poética silva: un manuscrito granadino del Siglo de Oro. Córdoba: Universidad de Córdoba.

Pedraza Jiménez, Felipe B. (1993-1994). Ver Vega Carpio (1993-1994).

Profeti, Maria Grazia (1986). «Intertestualità e manierismo: il mal d'amore in Lope de Vega e Quevedo». En Daniela Dalla Valle (ed.), Manierismo e letteratura. Torino: Albert Meynier, pp. 535-550.

Rosell, Cayetano (ed.) (1856). Colección escogida de obras no dramáticas de frey Lope Félix de Vega Carpio. Madrid: M. Rivadeneyra.

SÁnChez JimÉnez, Antonio y Fernando Rodríguez-Gallego (eds.) (en prensa). Rimas, y otros versos. Madrid: Real Academia Española.

TESO: Teatro español del Siglo de Oro (1998). Carmen Simón Palmer (ed.). Madrid: Chadwyck-Healey España (CD-ROM).

Tubau, Xavier (2008). Lope de Vega y las polémicas literarias de su época: Pedro de Torres Rámila y Diego de Colmenares. Alberto Blecua (dir.) [tesis doctoral]. Bellaterra: Universitat Autònoma de Barcelona <https://www.tdx.cat/ handle/10803/4889\#page=162> [Consulta: 16/08/2019].

Vega CARPIO, Lope de (1951). Jerusalén conquistada: epopeya trágica. Joaquín de Entrambasaguas (ed.). Madrid: Consejo Superior de Investigaciones Científicas / Instituto Miguel de Cervantes, t. I.

Vega Carpio, Lope de (1954). Los Ramírez de Arellano: contribución al estudio de las comedias genealógicas de Lope de Vega. Diana Ramírez de Arellano (ed.). Madrid: Instituto de Estudios Madrileños del Consejo Superior de Investigaciones Científicas.

Vega Carpio, Lope de (1993-1994). Rimas. Felipe B. Pedraza Jiménez (ed.). S. L.: Universidad de Castilla-La Mancha.

Vega Carpio, Lope de (1998). Rimas humanas y otros versos. Antonio Carreño (ed.). Barcelona: Crítica.

Vega Carpio, Lope de (2011). La Dorotea. Donald McGrady (ed.). Barcelona: Galaxia Gutenberg / Real Academia Española.

Vega Carpio, Lope de (2012a). La fortuna merecida. Ana Isabel Sánchez (ed.). En Comedias de Lope de Vega. Parte XI. Laura Fernández y Gonzalo Pontón (coords.). Madrid: Gredos, II, pp. 611-790.

Vega CARPIO, Lope de (2012b). La locura por la honra. Florence d'Artois (ed.). En Comedias de Lope de Vega. Parte XI. Laura Fernández y Gonzalo Pontón (coords.). Madrid: Gredos, II, pp. 177-320. 
Vega CARPIO, Lope de (2013). Las flores de don Juan y rico y pobre trocados. Luis Sánchez Laílla (ed.). En Comedias de Lope de Vega. Parte XII. José Enrique Laplana Gil (coord.). Madrid: Gredos, II, pp. 155-336.

Vega CARPIO, Lope de (2015). La corona merecida. Fernando Rodríguez-Gallego (ed.). En Comedias. Parte XIV. José Enrique López Martínez (coord.). Madrid: Gredos, I, pp. 583-829.

Vega CARPIo, Lope de (2016a). El caballero del Sacramento. Marcella Trambaioli (ed.). En Comedias. Parte XV. Luis Sánchez Laílla (coord.). Madrid: Gredos, t. I, pp. 535-688.

Vega Carpio, Lope de (2016b). El peregrino en su patria. Julián González-Barrera (ed.). Madrid: Cátedra.

Vega Carpio, Lope de (2019). La campana de Aragón. Diego Símini (ed.). En Comedias. Parte XVIII. Antonio Sánchez Jiménez y Adrián J. Sáez (coords.). Madrid: Gredos, II, pp. 303-465.

Vega Carpio, Lope de (en prensa). El conde Fernán González. Omar Sanz Burgos (ed.). En Comedias. Parte XIX. Alejandro García-Reidy y Fernando Plata Parga (coords.). Madrid: Gredos. 


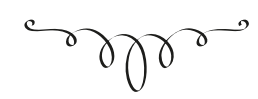

Algunas posibles enMiendas a las RIMAS De Lope a Partir De las Versiones tempranas

RESUMEN: Uno de los grandes hitos de la poesía de Lope de Vega fueron las Rimas, publicadas parcialmente en 1602 (los doscientos sonetos) y en su forma definitiva en 1604 . Hasta la fecha, las ediciones modernas se han basado siempre en el texto de los impresos, por considerar que representan la voluntad última de Lope, aunque discrepen sobre si dar preeminencia a la edición de 1604 o a la de 1609. Sin embargo, en este artículo se analizan algunos loci critici de las Rimas en los que quizá la variante de los impresos se deba a un error introducido en la imprenta, por lo que habría de enmendarse el texto de acuerdo con la de algún testimonio anterior.

Palabras clave: Lope de Vega, Rimas, crítica textual, poesía del Siglo de Oro.

\section{SOME POSSIBLE AMENDMENTS TO LOPE's RIMAS BASED ON EARLY VERSIONS}

AвSTRACT: One of the great milestones of Lope de Vega's poetry were the Rimas, published partially in 1602 (the two hundred sonnets) and in its final form in 1604. To date, modern editions have always been based on the text of the old printed editions, considering that they represent the last will of Lope, although they disagree on whether to give prominence to the 1604 or 1609 edition. However, in this article I analyse some loci critici of the Rimas in which perhaps the variant of the editions is due to an error introduced in the press, so that the text should be amended according to the variant of a previous witness.

Keywords: Lope de Vega, Rimas, Textual Criticism, Spanish Poetry of the Golden Age. 